\title{
Analysis of aerosol optical depth evaluation in polar regions and associated uncertainties
}

\author{
P. Ortiz de Galisteo ${ }^{1,2}$, C. Toledano ${ }^{1}$, V. Cachorro ${ }^{1}$, E. Rodríguez ${ }^{1}$, and A. de Frutos ${ }^{1}$ \\ ${ }^{1}$ GOA-UVA Atmospheric Optics Group of the University of Valladolid, Spain \\ ${ }^{2}$ INM National Institute of Meteorology, Madrid, Spain
}

Received: 23 December 2007 - Revised: 8 March 2008 - Accepted: 17 March 2008 - Published: 7 April 2008

\begin{abstract}
Some available processing algorithms used to calculate the aerosol optical depth from radiometric measurements were tested. The aim was to evaluate the associated uncertainties in polar regions due to the data processing, in order to adjust the methodology of the calculation and illustrate the importance of these error sources. The measurements were obtained during a sun photometer campaign in Ny-Ålesund within the framework of the POLAR-AOD project.
\end{abstract}

\section{Introduction}

The radiative forcing of atmospheric aerosols constitutes one of the main uncertainties in climate change studies. Understanding the role of aerosols in polar regions, where the climate change has been seen to be more intense, is especially relevant. Thus, within the framework of the International Polar Year 2007/08, the project POLAR-AOD attempts to establish a bipolar network to characterize the climate-forcing properties of aerosols in polar regions.

The first activity within POLAR-AOD was a sunphotometer campaign that took place in $\mathrm{Ny}$-Ålesund ( $78^{\circ} 55^{\prime} \mathrm{N}-11^{\circ} 54^{\prime} \mathrm{E}$, Svalbard) in spring 2006. One of the aims of this campaign was to adjust the calculation procedure for the aerosol optical depth (AOD) in order to achieve homogeneous AOD evaluations.

Typical values of AOD (500nm) are between 0.02 and 0.08 in Antarctica, and between 0.03 and 0.10 in the Arctic (Tomasi et al., 2007). Due to these low values and to the critical observation conditions the final uncertainty in the AOD can be very significant.

\section{Methodology}

The study of atmospheric components by radiometric measurements is based on the comparison between the solar irra-

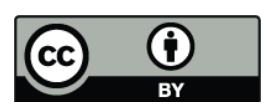

Correspondence to: P. Ortiz de Galisteo (jportiz@goa.uva.es) diance on the Earth's surface (I) and the extraterrestrial solar spectrum $I_{0}$ (Shaw, 1983):

$I=I_{0} \cdot e^{-\tau m}$

The difference between $I_{0}$ and $\mathrm{I}$ is due to the attenuation throughout the atmosphere produced by: Rayleigh molecular scattering, aerosol scattering and absorption, and absorptions by gases. The air mass (m) accounts for the light path through the atmosphere with respect to the vertical path.

The $\operatorname{AOD}\left(\tau_{a}\right)$ is calculated after subtracting from the total optical depth $(\tau)$ the contribution of the other atmospheric components: molecules $\left(\tau_{R}\right)$, ozone $\left(\tau_{\mathrm{O}_{3}}\right)$, water vapour $\left(\tau_{w v}\right)$, and other gases $\left(\tau_{g}\right)$. Thus, its accuracy is affected by errors in the other components.

All the atmospheric constituents are not equally distributed, so the air mass, which depends on the vertical profile, is different for each of them.

$\tau m=\tau_{R} m_{R}+\tau_{a} m_{a}+\tau_{\mathrm{O}_{3}} m_{\mathrm{O}_{3}}+\tau_{g} m_{g}+\tau_{w v} m_{w v}$

From expressions (1) and (2),

$\tau_{a}=\left(\operatorname{Ln}\left(I_{0} / I\right)-\tau_{R} m_{R}-\tau_{\mathrm{O}_{3}} m_{\mathrm{O}_{3}}-\tau_{g} m_{g}-\tau_{w v} m_{w v}\right) / m_{a}$

\section{Results and discussion}

The following results were achieved from the data obtained with a Cimel sun-photometer, which is the standard instrument of AERONET (Aerosol Robotic Network, http:// aeronet.gsfc.nasa.gov/), during the sun photometer campaign in Ny-Ålesund. 
Table 1. Differences in the AOD for each working wavelength due to the discrepancies in the SZA at the observation time computed from the formulas of Spencer and Michalsky.

\begin{tabular}{lcccccccc}
\hline Wavelength & 1640 & 1020 & 870 & 675 & 500 & 440 & 380 & 340 \\
\hline bias & 0.000 & 0.000 & 0.000 & 0.000 & 0.001 & 0.001 & 0.002 & 0.003 \\
RMSE & 0.000 & 0.000 & 0.000 & 0.000 & 0.001 & 0.001 & 0.002 & 0.004 \\
maximum & 0.001 & 0.001 & 0.001 & 0.001 & 0.003 & 0.004 & 0.006 & 0.010 \\
\hline
\end{tabular}

Table 2. Dissimilarities in the AOD for each working wavelength considering or not the light refraction due to discrepancies in the SZA.

\begin{tabular}{lcccccccc}
\hline Wavelength & 1640 & 1020 & 870 & 675 & 500 & 440 & 380 & 340 \\
\hline mean & 0.000 & 0.000 & 0.000 & 0.001 & 0.002 & 0.002 & 0.004 & 0.006 \\
maximum & 0.001 & 0.001 & 0.001 & 0.002 & 0.004 & 0.005 & 0.008 & 0.012 \\
\hline
\end{tabular}

NyAlesund campaign: AOD Statistics (maximum, miminum, and mean +1. standard deviation)

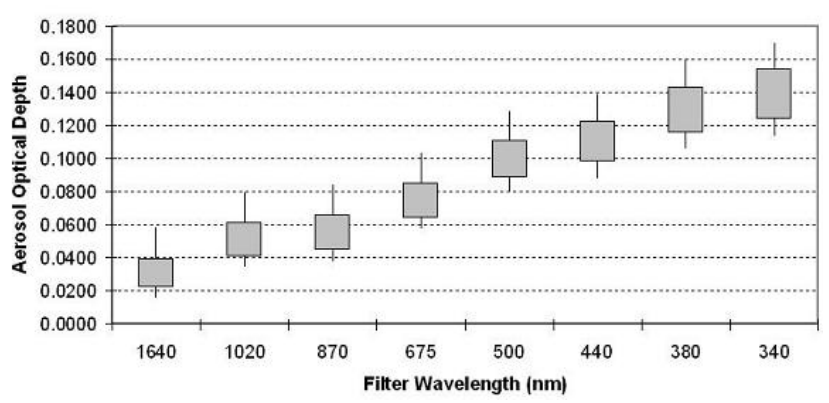

Figure 1. Statistics values: maximum, minimum and mean $+/-$ standard deviation of the aerosol optical depth for the whole campaign for each working wavelengths.

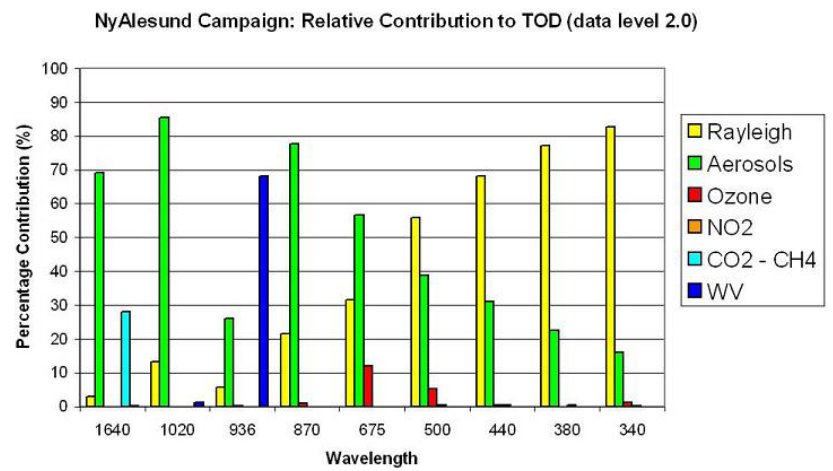

Figure 2. Relative contribution (\%) of each atmospheric component to the total optical depth for each wavelength (nm). Graph obtained with the measurements taken during the Ny-Ålesund campaign (data level 2.0: after cloud screening).
In this paper we focus our interest on the uncertainties in the data processing. According to expression (3) and ignoring other error sources like calibration and instrument characteristics, the errors will be associated with the contribution of other atmospheric constituents and the air mass calculation, which for its part is affected by astronomical coordinates and light refraction.

The AOD was computed with a software package developed by us based on the algorithms used in the new AERONET processing version 2 (Smirnov, 2004). Figure 1 shows the mean AOD in each spectral channel, as well as the standard deviation, maximum and minimum. The mean AOD $(500 \mathrm{~nm})$ was 0.1 , just on the limit between clear and haze conditions in the arctic (Tomasi et al., 2007). Figure 2 represents a breakdown in the percentages of the relative contribution of each atmospheric component to the total optical depth (TOD) for each wavelength. This analysis is useful in helping to understand the importance of each error source. Thus, in the ultraviolet range even a small error in the Rayleigh OD can result in large AOD error. Other algorithms were subsequently introduced in the data processing to study their contribution to the uncertainty in the AOD. These will be analyzed in the following sections.

\subsection{Astronomical coordinates}

The exact astronomical parameters at the observation time are difficult to determine due to the complexity of several movements that affect the Sun and the Earth. Therefore, in the literature approximation formulas have been proposed to calculate these parameters. In this study two of them were used: Michalsky (1988) and Spencer (1971). Some discrepancies $\left(\right.$ bias $=2.8^{\prime} ; \mathrm{RMSE}=3.6^{\prime} ; \max =6.9^{\prime}$ ) were obtained in the solar zenith angle (SZA), which were maximum at sunrise, producing discrepancies in the values of the AOD (Table 1). 
Table 3. Differences between the AOD for each working wavelength calculated considering the same air mass for all the atmospheric components and a different one for each of them.

\begin{tabular}{lcccccccc}
\hline Wavelength & 1640 & 1020 & 870 & 675 & 500 & 440 & 380 & 340 \\
\hline bias & 0.001 & 0.001 & 0.001 & 0.000 & 0.001 & 0.002 & 0.002 & 0.002 \\
RMSE & 0.001 & 0.001 & 0.001 & 0.001 & 0.001 & 0.002 & 0.002 & 0.002 \\
maximum & 0.002 & 0.002 & 0.002 & 0.002 & 0.003 & 0.004 & 0.005 & 0.005 \\
\hline
\end{tabular}

Table 4. Rayleigh optical depth for each working wavelength $(\mathrm{nm})$ calculated according to the formulas of different authors.

\begin{tabular}{lcccccccc}
\hline & 1640 & 1020 & 870 & 675 & 500 & 440 & 380 & 340 \\
\hline Bodhaine & 0.001 & 0.008 & 0.015 & 0.042 & 0.145 & 0.242 & 0.443 & 0.719 \\
Fröhlich and Shaw & 0.001 & 0.008 & 0.015 & 0.042 & 0.144 & 0.243 & 0.444 & 0.721 \\
Gueymard & 0.001 & 0.008 & 0.015 & 0.042 & 0.144 & 0.242 & 0.442 & 0.717 \\
Bird and Riordan & 0.001 & 0.008 & 0.016 & 0.042 & 0.146 & 0.246 & 0.449 & 0.729 \\
Hansen and Travis & 0.001 & 0.008 & 0.015 & 0.042 & 0.145 & 0.243 & 0.444 & 0.720 \\
\hline
\end{tabular}

\subsection{Light refraction}

Light refraction makes the Sun appear in an apparent position with a SZA lower than the real one. The lower the temperature and the higher the SZA, the larger the refraction. Both conditions are especially relevant in polar regions, so this effect is important and must be taken into account.

Two expressions were adopted to determine the effect of light refraction: Meeus (1991) and US Standard Atmosphere (1976), resulting in a discrepancy between the SZA calculated with bias $=39^{\prime \prime}$ and $\max =1^{\prime}$. Only Meeus' one takes into account the temperature and pressure at observation time. Despite this, no significant dissimilarities were found in the AOD. Nevertheless if refraction had not been considered, the error in the SZA (with a mean value of $5^{\prime}$ and a maximum of $12.5^{\prime}$ ) would have produced a significant error in the AOD (Table 2).

\subsection{Air mass}

In this point we want to illustrate the importance of taking into account the non-equal distribution of the atmospheric constituents, especially for observations at high SZA as is the case in polar regions.

The AOD was calculated using the same air mass for all the atmospheric components (Kasten and Young, 1989), and a different one for each of them: molecular (Kasten and Young, 1989), ozone (Komhyr, 1989), water vapour and aerosols (Kasten, 1966). The highest discrepancy was 0.005 (Table 3). These differences decrease from sunrise, reach a minimum at noon, and increase until sunset, due to the fact that for small SZA the air mass of each component tends to the same value.
In any case the approximation formulas of air masses used were developed for mid-latitude atmospheres, and they probably would need to be adapted to an arctic one.

\subsection{Rayleigh scattering}

Many expressions for Rayleigh scattering have been proposed in the literature. Five of them were tested: Fröhlich and Shaw (1980), Bird and Riordan (1986), Gueymard (1995), Hansen and Travis (1974) and Bodhaine et al. (1999). Differences as high as 0.012 in $340 \mathrm{~nm}$ were obtained (Table 4).

To compute the Rayleigh scattering it is necessary to know the pressure at the observation site. Normally, if pressure data at the observation time is not available, climatological values are used. Both kinds of pressure data were tested resulting in discrepancies of $10 \mathrm{hPa}$, about 0.007 in the Rayleigh optical depth and therefore in the same magnitude in the AOD.

\subsection{Ozone and nitrogen dioxide}

The largest error in the ozone and $\mathrm{NO}_{2}$ optical depth comes from the uncertainty in their columnar content. In the same way as with the pressure (see above), observed and climatological data for columnar content were used. In the case of ozone, differences as high as 60DU were detected, causing a discrepancy of 0.003 in the absorption by ozone in $675 \mathrm{~nm}$ and consequently in the AOD. However, in the case of $\mathrm{NO}_{2}$ its contribution is much less important and the discrepancies are negligible. 


\section{Conclusions}

The magnitude of the uncertainties of the data processing is small, but due to the low pollution levels in polar regions and to the extreme observation conditions they can involve a high percentage in the value of the AOD in these regions. So the data processing to evaluate the AOD must be accurately accomplished, otherwise the errors can be as large as the variable that we intend to determine.

The errors caused by the processing, especially those related to the astronomical data, the refraction, the air mass and the Rayleigh scattering are reduced just by using stateof-the-art algorithms. Observed data of ozone and pressure are basic requirements to achieve the necessary accuracy in the AOD calculation in polar regions.

Acknowledgements. We are grateful to the following institutions for organizing and participating in the Ny-Alesund sun photometer intercomparison campaign: Institute of Atmospheric Sciences and Climate (CNR Bologna), Alfred Wegener Institute (Germany), University of Sherbrooke (Canada), Finnish Meteorological Institute, Institute of Oceanology of the Polish Academy Science (Sopot), Norwegian Institute of Air Research, Andoya Rocket Range (Norway), National Institute of Polar Research (Japan), Institute for Tropospheric Research (Leipzig), National Oceanic \& Atmospheric Administration (Boulder, US), University of Bremen (Germany).

Edited by: M. Piringer

Reviewed by: two anonymous referees

\section{References}

Bird, R. E. and Riordan, C.: Simple solar spectral model for direct and diffuse irradiance on horizontal and tilted planes at the Earth's surface for cloudless atmospheres, J. Clim. Appl. Meteorol. 25, 87-97, 1986

Bodhaine, B. A., Word, N. B., Dutton, E. G., and Slusser, J. R.: On Rayleigh Optical Depth Calculations, J. Atmos. Ocean. Tech, 16, 185-1861, 1999.
Fröhlich, C. and Shaw, G. E.: New determination of Rayleigh scattering in the terrestrial atmosphere, Appl. Optics, 19, 1773-1775, 1980.

Gueymard C.: SMARTS2 A simple model of atmospheric radiative transfer of sunshine, Report FSEC-PF-270-95, Florida Solar Energy Center, 1995.

Hansen, J. E. and Travis, L. D.: Light Scattering in Planetary Atmospheres, Space Sci. Rev. 16, 527-610, doi:10.1007/BF00168069, 1974.

Kasten, F. and Young, A. T.: Revised optical air mass tables and approximation formula, Appl. Optics, 28, 4735-4738, 1989.

Kasten, F.: A new table and approximation formula for relative air mass, Arch. Meteor. Geophysics. Bioklimatol. Ser. B, 14, 206223, 1966.

Komhyr II, D., Grass, K. D., and Leonard, R. K.: Jonson Spectrophotometer 83: a Standard for total ozone measurements, 1962-1987, J.Geophys. Res., 94, 9847-9861, 1989.

Meeus, J.: Astronomical Algorithms, Willmann-Bell, 102 pp., 1991.

Michalsky, J.: The astronomical almanac's algorithm for approximate solar position (1950-2030), Solar Energy, 40, 227-235, 1998.

Shaw, G. E.: Sun photometry, B. Am. Meteorol. Soc., 64, 4-10, 1983

Smirnov, A., Holben, B. N., Lyapustin, A., Slutsker, I., and Eck, T. F.: AERONET processing algorithms refinement, AERONET Workshop, May 10-14, 2004, El Arenosillo, Spain.

Spencer, J. W.: Fourier series representation of the position of the sun, Search, 2, p. 172, 1971.

Tomasi, C., Vitale, V., Lupi, A., et al.: Aerosols in polar regions: A historical overview based on optical depth and in situ observations, J. Geophys. Res., 112, D16205, doi:10.1029/2007JD008432, 2007. 